\title{
Nutritional Status of Tribal Women of Reproductive Age Group in Naugarh Block, Chandauli District, India
}

\author{
Namita Singh* \\ Department of Food Science and Nutrition, Central Agricultural University, Tura, \\ Meghalaya, India \\ *Corresponding author
}

\begin{tabular}{|l|}
\hline Ke y w or d s \\
BMI, CED, Clinical \\
examination, \\
Anthropometric \\
measurement, \\
Haemoglobin \\
\hline Article Info \\
\hline $\begin{array}{l}\text { Accepted: } \\
\text { 10 June } 2019 \\
\text { Available Online: } \\
\text { 10 July } 2019\end{array}$ \\
\hline
\end{tabular}

\section{Keywords}

BMI, CED, Clinical

examination, Anthropometric measurement, remoglobin

10 July 2019

\section{A B S T R A C T}

The main objective of this study was to assess nutritional status of the study subject. This was a cross-sectional study. Four hundred and two females (i.e. 15-49 age groups) were selected from 342 households for assessment of nutritional status. Stratified random sampling method was used for selection of seven villages. Families were selected by using Probability Proportion to size sampling technique. The primary tool in this study was predesigned and pretested interview schedule. Height, weight recording, Clinical examinations and body type of females were the part of the study. One hundred and three study subjects were randomly selected and haemoglobin was estimated. Slightly less than half $(46.8 \%)$ study females were short stature and thin. Clinical anaemia (67.7\%), Vitamin A (15.9\%) and vitamin C deficiency $11.2 \%$ were common nutritional deficiency diseases. The mean weight of the study subjects was $41.5 \mathrm{Kg}$. The vast majority (approximately $85 \%)$ of females had weight less than the weight of the reference women $(50 \mathrm{Kg})$. The mean body mass index was 18.7. Only one -fifth (20.0\%) of the study subjects were normal (BMI-20.0 - 25.0). More than half $(56.7 \%)$ of the study women suffered from chronic energy deficiency (BMI <18.5). Nearly nine-tenth $(89.3 \%)$ women were found anaemic according to the cut-off point $(\mathrm{HB}<12.0 \mathrm{gm} / \mathrm{dl})$ proposed by WHO. The overall nutritional status of the tribal females was poor. Nutritional anaemia, vit-A and vit-C deficiencies was important problems in the study subjects. Majority of tribal females was underweight and stunted. Prevalence of chronic energy deficiency was high.

\section{Introduction}

Since the inception of the planning process in the country, emphasis was put on socioeconomic development. Health was given a high priority in the scheme of socioeconomic development because it was considered not only one of the desirable ends in itself for raising the quality of life but was also recognized as a major instrument of the developmental process (Murali, 1988). Highest priority was accorded for the improvement of maternal and child health with a special focuses on the less privileged sectors of the society (Government of India, 1983). It is estimated that the tribal population constitute 8.6 percent of the total population of India. This population enlists under condition of severe socio-economic stress and hence more vulnerable to malnutrition and 
related health problems.). It has been recently suggested that it is imperative to evaluate the nutritional status of the various unexplored tribes of India especially Eastern India which is relatively ignored. Undernutrition/malnutrition remains to be an everlasting problem in Asian countries (Ghosh, 2006).

Females experience more episodes of illness as compared to their male counterparts and are less likely to receive medical treatment before the illness is well advanced, because the nutritional status of women is compromised by unequal access to food, by heavy work demands and by special nutritional needs, females are particularly susceptible to illness. Women, especially poor women and belonging to tribal areas are often trapped in a cycle of ill heath, exacerbated by child bearing and hard physical labour (World Bank, 1996). A tribal woman occupies an important place in the socio-economic structure of her society. However, it has been observed that the status of tribal women is comparatively lower than that of tribal men (Basu, 2001).

Tribal women in India are at great disadvantage due to illiteracy and ignorance. The women centered tribal economy has received global recognition. Through the findings of different studies and observations, it is well accepted that tribal women contribute more than men in almost allimportant activities. Because of deforestation, the distance between the villages and the forest areas have increases, which has further widened the gap between tribal women's way of life and their economic dependency (Singh, 2001). With this background this study was carried out in Naugarh Community Development Block of Chandauli District, Uttar Pradesh (U. P.) with the objective to assess nutritional status of the study subjects.

\section{Materials and Methods}

The present study was carried out in seven remote villages with a high percentage of tribal population. Villages were selected by stratified random sampling. Stratification was done on the basis of distance from the block head quarter. This was the cross sectional study. Four hundred two females were studied from Three Forty Two households. Families were selected by using probability proportional to size (PPS) sampling technique. Tribal women belonging to reproductive age group i.e. 15-49 years were considered as eligible females. The primary tool in the study area was a predesigned and pretested interview schedule. Weighing machine and steel anthropometric rod with parallel bars were utilized for anthropometric measurements viz. weight and height recording.

Information related to clinical examination, anthropometric measurements, was obtained from all female study subjects. Only hundred and three study subjects (excluding pregnant women) were randomly selected for the estimation of their haemoglobin. Each subject was examined clinically by the researcher for the presence of signs of nutritional deficiency disease viz. Vit-A, B, C, D deficiencies, anaemia, IDD and fluorosis. For this purpose, a 'check list' had been used. Height and weight of the study subjects were recorded by following standard techniques (Jelliffee, 1966). Accuracy of weighing machine had verified periodically by cross checking with a standard weight. The weight had been recorded to the nearest half kilogram with zero error corrected each time. The height readings were noted in cms giving accuracy to one decimal points. Before the haemoglobin testing was undertaken the study subjects were explained and asked for the test. In some cases study subjects were not interested. The remaining subjects were considered for the 
estimation of haemoglobin. Haemoglobin was estimated by Sahli's method.

\section{Results and Discussion}

\section{Nutritional status of study subjects}

Nutritional assessment reflects the nutritional health of an individual. The result obtained in this study through nutritional assessment afforded the opportunity for early detection of undernourished tribal females and for the development of intervention programmes in the community as well as for the planning and implementation of nutritional care of these females by the administration. Some salient findings are

\section{Clinical examination}

Clinical examination is an essential feature of all nutritional surveys. It is also the simplest and the most practical method of ascertaining the nutritional status of a group of individual.

\section{General appearance of the females}

General inspection and care full attention to the presence and distribution of body fat, the muscle bulk and the presence of oedema is the important part of clinical examination (Habicht, 1989) Table 1 shows the findings obtained in the general assessment of nutritional status of the tribal females.

The result shows that $46.8 \%$ of the study subjects were short in height and thin in built. This indicates that nearly half of the females were undernourished. Furthermore, 15.7\% females were of average height and thin which also adds to the percentage of undernourished females. Only $12.0 \%$ of females were of average height and weight. These findings are similar to the results obtained in the study conducted by Saha (1980) on Muria tribe at Narayanpur, Bastar, found that maximum percentage of females $(45.8 \%)$ were short stature. They were followed by below medium stature women $(26.1 \%)$ and only $17.0 \%$ of women were medium stature. Haque and Samanta (1998) also reported similar results in their study conducted on Kora of Bankura, west Bengal. The result shows that $46 \%, 22 \%$ and $14.0 \%$ females were short, below medium and medium stature respectively. According to the survey conducted by Indian Council of Social Science Research 48.53 percent respondents stated that women serve the family first and eat last. In poor families this results in greater malnutrition of women (Ghosh, 2006). In a study by (Choudhary and Dashora, 2015 clinical sign symptoms shows that no one was affected from breathelessness but 20 percent feel weak and 20 percent had thin hair. Twenty percent subjects had a problem rapid heartbeat, 4 percent of people responded for easy fatigue. Pallor of Conjunctiva, nail beds, lips, oral mucosa, has been used in diagnosis of anemia.

\section{Nutritional disease}

There are a number of detectable physical signs known to be associated with states of malnutrition and various nutritional diseases can be detected on careful physical examination. Table 2 shows the proportion of females suffering from various nutritional diseases detected during clinical examination

More than two- third (67.7\%) females were found clinically anaemic reflecting the most common nutritional disease in the area. Vit-A $(15.9 \%)$ and vit-C deficiency (11.2\%) were the next two common nutritional diseases present in the area. However, the actual figures must be relatively high as mild and subclinical diseases are often missed on clinical examination. Jelliffe (1966) also reported that detection of nutritional diseases on clinical examination indicates their 
moderate to severe from. Symptoms of night blindness and / or conjunctival xerosis were found in $15.9 \%$ of the females, However, Bitot's spots, corneal xerosis or ulceration was not found in any of the study subject. While there is common consensus about high prevalence of vit A deficiency in children in tribal areas the opinion differs in case of adults. Rao et al (1993) reported maximum prevalence $(2.1 \%)$ of Bitot's spot among school age in Jenu Kurubas tribe of Karnataka. Bitot's spot was not found in any adult among Oraon tribe of Bihar (Chandrasekhar et al., 1997) and Jenu Kurubas tribe Karnataka (Rao, et al., 1993). However, a very high percentage $(9.5 \%)$ of Bitot's spot was reported in rural Oria mother (Mohapatra et al., 2001). Other tribal studies reported varying proportion of adults suffering from vit-A deficiency, which were 12.7\% (Chandrasekhar et al., 1997), 30\% (Prema and Thomas, 1992) and 33\% (Sharma and Sharma, 1993). The reason behind this might be the less intake of beta carotent and vitamin $-\mathrm{A}$ rich food.

This is also true for vit-c deficiency. Though in some tribal areas the average consumption of vit-C far exceeded the Recommended Daily Allowances (Bagchi 1994; Prema and Thomas, 1992) this was not true in case of present study where $11.2 \%$ females were found vit-C deficient. Kupputhai and Mallika (1993) also found that intake of vit-C was more deficient among tribal women. Prevalence of spongy and / or bleeding gum were very high $(48.4 \%$ and $25.4 \%)$ among Oraon tribes of Bihar (Chandrasekhar et al, 1997) and the reason for it were Vit -C deficient diet and tobacco chewing.

As expected iron deficiency anaemia was the commonest and most prevalent nutritional deficiency disease in the study area, which constituted more than two third (67.7\%) females. Though Haemoglobin level estimation is considered as gold standard for making the diagnosis of anaemia, the detailed clinical examination has its own value and even in national CSSM programme (Government of India, 1994) it was accepted and appreciated. Almost all tribal studies reported very high percentage of anaemic people in their study area (Chandrasekhar et al., 1997; Kaur et al., 1984; Kumar et al., 1989; Kupputhai and Mallika, 1993; Maiti and Unisa, 2003; NFHS-3 2005-06; Prema and Thomas, 1992; Rao et al., 1993; Rao et al., 1998; Sharma and Sharma 1993). The proportion ranged from $32 \%$ females in Adhaura, Bihar (Kaur et al., 1984) to $100 \%$ pregnant and non-pregnant adult women (Chandrasekhar et al., 1997; Rao 1993). The clinical symptoms and signs of anaemia observed may be a result of low haemoglobin levels which occur in turn due to low intake of green leafy vegetables and other foods rich in iron.

Teeth mottled enamel was found in $5.2 \%$ of the study subjects. This sign of fluorine excess is attributed to most abundant occurrence of fluorine in drinking water in the study area. In a previous study in the same area, overall prevalence of fluorosis was $12.75 \%$ (Singh, 1997). However in the present study the figure is $5.2 \%$ among the females of reproductive age groups, this is because many females migrated to other places after marriage and vice-versa, which brought the figure down.

Other symptoms and signs suggestive of nutritional deficiency viz: Corneal xerosis/ulceration, Bitot's spot, goiter and skeletal disorders were not found among the study subjects. Though a variety of green leafy and other vegetables, fruits and animal products are available in the study area, it is due to lack of knowledge and poor intake of these foods by the females, they suffer from various nutritional deficiency diseases. Rao 
K.M et al 2010 reported that the deficit was more with respect to micronutrients such as iron, vitamin A, riboflavin and free folic acid. The deficit in protein and energy intake was more among pregnant and lactating women, when compared to NPNL women in both tribal and rural areas. With regard to proteincalorie adequacy status, in general, about $80 \%$ of NPNL women and 58-60\% of the pregnant and lactating women consumed adequate amount of both protein and energy $(\mathrm{P}+\mathrm{C}+)$.Distribution of women according to intake of nutrients less than $50 \%$ of RDA revealed that more than $70 \%$ of the women were not meeting even $50 \%$ of the requirement for iron and vitamin $\mathrm{A}$ in both areas. Similar observation was also made with respect to free folic acid, which ranged from $54 \%$ to $100 \%$ among tribal and rural women.

A study carried out by NNMB (2003) revealed that the overall prevalence of anaemia was observed to be highest among lactating women $(78 \%)$ followed by pregnant Women (75\%) and adolescent girls (70\%).Also the prevalence of micronutrient deficiencies revealed that the overall prevalence of anaemia was observed to be highest among lactating women (78\%) followed by pregnant Women (75\%) and adolescent girls (70\%).

\section{Anthropometric measurement}

Nutritional anthropometry is an important criterion for judging nutritional status as it provides evidence of under nutrition. Height is a measure of growth of the body and the degree of skeletal development and weight is a measure of total body mass. There are various indices available for classifying nutritional status viz. Pelidisi Index, Korperfulla Index, Quallet index, Body Mass Index, Pignet Index etc (Haque and Samanta, 1998). Of these Body Mass Index is most frequently used by researchers and many authors proposed it as a good index to assess the current forms of malnutrition in a community (Kupputhai and Mallika, 1993; Mohanty et al., 1992). The cut-off point for weight and height, below which a women can be identified as nutritionally at risk varies among population. Several cut-offs have been used to screen mothers at risk of having pregnancy complication. Most studies from India and other developing countries have used $<145 \mathrm{~cm}$ for height and 38-40 Kg for weight as cut-offs for screening high-risk mothers (Krasovec, 1991). Table 3 shows the distribution of weight and height of the study subjects. Darl T A et al., 2017 reported that in case of tribal reproductive women, the mean height was 5.54 inches, mean weight was $60.69 \mathrm{Kg}$ and mean BMI was 21.37 while as in case of non tribal reproductive women, the mean height was 5.61 inches, mean weight was $62.08 \mathrm{Kg}$ and mean BMI was 21.28. In another study by Dobhal, Raghuvanshi (2011) the mean body height, weight, MUAC and BMI of urban women were $12 \mathrm{~cm}, 1.6 \mathrm{~kg}$, $24.0 \mathrm{~cm} 21.89 \mathrm{~kg} / \mathrm{m} 2$ respectively and 153.8 $\mathrm{cm}, 49.8 \mathrm{~kg}, 23.7 \mathrm{~cm}$, and $20.7 \mathrm{~kg} / \mathrm{m} 2$ respectively for rural women.

The results revealed that for MUAC, 14.43 percent urban and 24.40 percent rural women and for TSF, 17.73 percent urban and 29.96 percent rural women were at risk of malnutrition as they had a MUAC and TSF less than the percentile. Also (Darl T.A. et al., 2017) found that in case of tribal reproductive women, the majority of the respondents 21 percent were undernourished under the 18-27 years age group and lowest 13 percent of the respondents belongs to the above 47 years age group while as in case of non tribal's the majority of the respondents 16.1 percent belongs to undernourished under the 18-27 years age group and lowest 8 percent of the respondents belongs to above 47 years age group. 


\section{Weight}

The mean weight of non-pregnant women was 41.5 K.G., which was much less than the weight of $(50 \mathrm{Kg}$.) reference women (ICMR, 1990) but this was relatively safe (more than $40 \mathrm{Kg}$ ) when risk of pregnancy complications were considered. Proportion wise nearly onefourth $(23.3 \%)$ females had weight below the cut-off point for mothers at risk and about $85.0 \%$ of females weighed less than the weight of reference women $(50 \mathrm{~kg})$. If $<45 \mathrm{~kg}$ is taken as a cut-off about two third (66.9\%) of females would be categorized as low weight. This figure is relatively low in comparison to two other tribal studies where percentage of low weight non pregnant and non lactating women (less than $45 \mathrm{~kg}$ ) were found to be $75.45 \%$ among Bhil women in Jhabua district of Madhya Pradesh (Taneja and Saxena, 1998) and 95.9\% among tribal women in Singhbhum district of Bihar (Tanuja et al, 1995) respectively. However, nearly one-fourth $(23.3 \%)$ females in this study whose weight were less than $40 \mathrm{Kg}$ were at substantially risk for future pregnancy complication.

\section{Height}

The height of an adult is an outcome of several factors including nutrition during childhood and adolescent. The heights of study subjects ranged from $143 \mathrm{~cm}$ to $165 \mathrm{~cm}$ with a mean height of $151.3 \mathrm{~cm}$. It is commonly believed that women in all tribal areas are shorter than their state or national figures. Many literatures on tribal studies also support this belief (Chandresekhar et al., 1997; Kupputhai and Mallika, 1993; Moitra and Choudhary, 1991; Mohapatra et al., 2001; Maiti and Unisa, 2003; Ray et al., 1999; Tanuja et al., 2001). The average height of adult females in these tribal studies ranged from 134.9 in Saurias Pahariya tribe of Rajmahal hills in Bihar (Moitra and
Choudhary, 1991) to 149.9 in tribal areas of Jharkhand (Maiti and Unisa, 2003). However, mean heights of adult tribal women more than $150 \mathrm{~cm}$, the height of reference women as described by ICMR (1990) are not uncommon in some tribal areas. Mohanty et al., (1992) found that the mean height of adult females of Bhuiya and Khariya tribes of Sundargarh district of Orisa were 151.15 and $151.13 \mathrm{~cm}$ respectively. Furthermore, in the studies conducted on tribal females on Gogunda village of Rajasthan (Smitha and Mathew, 1998) and on tribal population of Bastar district of Madhya Pradesh (Basu, 1992), it were found that the tribal females in these areas, by the age of 18 years, attained the heights of $115.87 \mathrm{~cm}$ and $153.0 \mathrm{~cm}$. respectively. These values of mean heights of tribal females are fairly higher than that of national figures and height of reference women i.e. $150 \mathrm{~cm}$ (ICMR, 1990), However, in the present study, the mean height of females is not as high as these studies and the difference in the mean heights of study subjects and that rural U.P. $(150.2 \mathrm{~cm})$ are not large. (NFHS-2, 1998-99).

About 36\% females in the present study had height less than $150 \mathrm{~cm}$, the height for reference women. If less than $145 \mathrm{~cm}$. is taken as a cut-off point for short stature then $6.2 \%$ of the tribal women in this study can be termed as short statured. In study conducted by Tanuja et al., (2001) on tribal women in singhbhum district of Bihar state, the percentage of women below $145 \mathrm{~cm}$. of height was found to be as high as $23.9 \%$. These women are at risk of having a difficult delivery, since small stature is often related to small pelvic size. The risk of having a baby with a low birth weight is also higher for mothers who are short (NFHS -3, 2005-06). However, maternal height does not have any significance on birth weight in low-income group (Taneja and Saxena, 1998). In present study, vast majority of women belong to low 
income group, therefore their heights have hardly any effect on birth weight of their babies, as later is influenced mainly by low income. Nonetheless $36 \%$ women with height less than $150 \mathrm{~cm}$ reflect under nutrition during their childhood and adolescent.

\section{Body mass index}

Body Mass Index is the most widely accepted and used index for assessing nutritional status of adult population. It is used as an index to assess the extent of Chronic Energy Deficiency (CED) in adults. Studies worldwide and from India have utilized BMI to study nutritional status of the tribal population. Therefore, the use of BMI and WHO BMI based cut-off point (Asian population) for the evaluation of undernutrition is expropriated for use among the tribal populations of India (Ghosh 2006). Patel and Deonanda Raywat (2017) stated that defining population nutritional status epidemiologically is innately problematic. But BMI is a useful first step and is commonly collected in many government-sponsored national health surveys. The threshold of obesity has been internationally accepted as a BMI of $\geq 30 \mathrm{~kg} / \mathrm{m}^{2}$.

Mohapatra et al., (2001) described CED as a good index to assess the current forms of malnutrition of adults. In this study, Chronic Energy Deficiency classification used in various tribal studies (Mohapatra et al., 2001, Taneja and Saxena 1998; Tanuja et al., 2001; Haque and Samanta 1998) was used. The results are shown in Table 4. On the other hand, the Chronic Energy Deficiency (CED) is associated with impaired physical capacity reduced economic productivity increased mortality and poorer reproductive outcomes. Some evidence in developing countries indicates that malnourished individuals, that is, women with a Body Mass Index (BMI) below $18.5 \mathrm{~kg} / \mathrm{m} 2$, show a progressive increase in mortality rates as well as increased risk of illness. It was found that in case of tribal reproductive women the BMI was higher 22.69 in above 47 year age group and lower 19.47 in the 28-37 years age group while as in case of non tribal reproductive women, the BMI was found to be higher 21.82 in above 47 years age group and lower 20.83 in the 28-37 years age group (Darl et al., 2017).

The mean body mass index of study subjects was 18.7, which was less than the mean BMI (20.0) for women in Uttar Pradesh. Chronic energy deficiency is usually determined by a BMI of less than 18.5 (NFHS-3, 2005-06) and females with BMI between 18.5 and 20.0 have been considered as Low weight-Normal. In this study, the mean BMI falls under low weight normal class group.

Haque and Samanta (1998) observed the mean BMI as low as 17.8 among Kora female of Bankura district of west Bengal. However, Maiti and Unisa (2003) found the mean BMI as high as 19.5 among tribal women in Jharkhand. Another study (Yadav et al., 1999) quoted that, in adults, Chronic Energy Deficient (CED) is higher in tribal district as compared to non tribal district. Further, the CED levels are higher for females as compared to males for both areas.

More than half $(56.7 \%)$ of study subjects were suffering from chronic energy deficiency (BMI < 18.5), this percentage is much higher in comparison to $36 \%$ of women as a whole in Uttar Pradesh (NFHS-3, 200506) in same class indicating a very high prevalence of nutritional deficiency in the study area. Laxmaiah et al., (2007) reported the prevalence of CED among adults was about $51 \%$ for both of the sexes. Little less figures has been reported by Rao et al., (2006) in his study on Saharia $(53.0 \%)$ the Primitive Tribe of Rajasthan. Furthermore, 
more than three-fourth $(76.2 \%)$ of study subjects had BMI lower than the cut-off point for deciding under nutrition (BMI < 20.0). Only $20.0 \%$ of females were normal in respect to nutritional status and $3.8 \%$ were obese. A very high percentage $(94.9 \%)$ of Bhil Women was found with BMI less than 20.0 in Jhabua district of Madhya Pradesh (Taneja and Saxena, 1998).

In the same study, it was found that $82.0 \%$ Bhil women were chronically nutritionally deficient (BMI <18.5). Several other tribal studies reported varying proportion of females with chronic energy deficiency viz Tanuja et al., (2001) 71.2\%, Haque and Samanta (1998) $68 \%$, Kupputhai and Mallika (1993) $88.9 \%$ to $94.7 \%$ in three different tribes, Maiti and Unisa (2003) 40.9\%. Also studies by (Dobhal and Raghuvanshi R.S., 2011) on the basis of prevalence of CED, the nutritional status of women of Uttarkashi was found better than status of women reported in the other studies.

In present study, among chronically nutritionally deficient women, maximum percentage $(33.3 \%)$ belonged to grade -I CED (mild malnutrition) followed by grade - II CED (12.1\%) and grade III CED (11.3\%). Similar results had been found by Mohapatra et al., (2001), Haque and Samanta (1998). Such a vast majority of women in study area with chronic energy deficiency i.e., BMI $<18.5(56.7 \%)$ and with under-nutrition i.e. BMI <20.0 (76.2\%) indicate a high prevalence of malnutrition in the study area.

The prevalence of CED was 56\% among tribal NPNL women against $36 \%$ in rural. Similarly, the prevalence of CED was high with $58 \%$ among tribal lactating women against $40 \%$ among rural lactating women. Women especially in younger age are at high obstetric risk (using the risk criteria of height less than $145 \mathrm{~cm}$ and weight less than $38 \mathrm{~kg}$ ) (Rao et al., 2010).

\section{Estimation of blood haemoglobin level}

Estimation of haemoblobin level is considered as gold standard for making the diagnosis of anaemia as it can detect even mild degree of anaemia even in clinically asymptomatic individual. Iron deficiency is the most widespread form of malnutrition in the world, affecting more than two billion people worldwide (Stolzfus and Dreyfuss, 1998) and $50 \%$ population in India (Seshadri, 1998). The condition is even worse in tribal areas.

In this study blood haemoglobin levels were estimated for only $25.8 \%$ non pregnant females due to scarcity of resources and at many places due to refusal by the study subjects NFHS-II (1998-99) report shows that in Uttar Pradesh, the haemoglobin levels were tested for only $64 \%$ of women, compared with $88 \%$ of women in India as whole. The haemoglobin levels of study subjects are presented in Table 5. According to Dobhal and Raghuvanshi (2011) prevalence of anaemia was assessed by estimating the haemoglobin concentration of the subjects and it was found to be 85 percent \pm with haemoglobin level ranging from 6.2 and $12.8 \mathrm{~g} / \mathrm{dl}$ with an average of $9.71 \pm 1.7 \mathrm{~g} / \mathrm{dl}$ for urban subjects and $10.48 \pm 1.79 \mathrm{~g} / \mathrm{dl}$ for rural subjects. Kamath (2013) reported that prevalence of anemia among the tribal people of Assam was 59.82\%, in Arunachal Pradesh $53.77 \%$ and Tripura $57.45 \%$.

In a study (Choudhary and Dashora, 2015) it was reported that compared to non-vegetarian (38 percent), more vegetarian 6.9 percent were anaemic. Nearly nine-tenth (89.3\%) females were found anaemic according to the cut-off point $(\mathrm{Hb}<12.0 \mathrm{gm} / \mathrm{dl})$ proposed by WHO expert group, (1968).

The mean haemoglobin level was 9.8, which ranged from 6.0 to $12.8 \mathrm{gm} / \mathrm{dl}$. Similar 
observation has been made by various authors in their tribal studies who found that more than $90 \%$ of tribal women had haemoglobin level less than 12.0 (Chandrasekhar, 1997; Rao et al., 1993; Rao, 1998). Three levels of severity of anaemia have been distinguished among adult non-pregnant women like: mild anaemia (10.0-11.9 gm/dl), moderate anaemia (7.0-9.9 $\mathrm{gm} / \mathrm{dl})$ and severe anaemia (less than $7.0 \mathrm{gm} / \mathrm{dl})$ (NFHS-3, 2005-06)

The figure shows that nine out of ten tribal women of Naugarh Block were anaemic as compared to only one out of two women in U.P. The low haemoglobin level in this vast majority of study subjects may be due to inadequate consumption of green leafy vegetables and fruits resulting in low intake of iron.

In addition, dietary pattern, poverty, ignorance by health care personnel etc. may be also responsible for very high prevalence of anaemia. About $58 \%$ of the study subjects were either moderately or mildly anaemic which is very high in comparison to the women of other tribal areas. This is a major cause of concern. According to the study by (Choudhary and Dashora, 2015) Among 48 percent of respondents who had normal weight according to their height 36 percent of them had low haemoglobin.

Although the weight may be normal, still anemia was found among them. Maximum percent of anemia prevalent in the age of 121 years. Also the females having 16-17 BMI were 4 percent mild anemic, and 2 percent were moderate anemic. The females having 17-18 BMI were 4 percent mild anemic, 6 percent moderate anemic, and 2 percent severe anemic. Similar studies by (Dobhal and Raghuvanshi (2011) stated that persons living at high altitudes have higher concentration of haemoglobin and RBCs than those living at the sea level.

Table.1 Distribution of females according to their general appearance on inspection

\begin{tabular}{|l|c|c|}
\hline General appearance & Number & Percent \\
\hline Tall and thin & 18 & 4.5 \\
\hline Tall and stout & 24 & 6.0 \\
\hline Short and thin & 188 & 46.8 \\
\hline Short and stout & 48 & 12.0 \\
\hline Short and average weight & 12 & 3.0 \\
\hline Average height and thin & 63 & 15.7 \\
\hline Average height and average weight & 49 & 12.0 \\
\hline Total & 402 & 100.0 \\
\hline
\end{tabular}

Table.2 Nutritional disease of study subjects $(n=402)$

\begin{tabular}{|l|c|c|}
\hline Nutritional disease & Number & Percent \\
\hline Vit-A deficiency & 64 & 15.9 \\
\hline Vit-B deficiency & 12 & 3.0 \\
\hline Vit-C deficiency & 45 & 11.2 \\
\hline Anaemia & 272 & 67.7 \\
\hline Fluorosis & 21 & 5.2 \\
\hline
\end{tabular}


Table.3 Distribution of females according to their weight, height excluding pregnant women $(n=390)$

\begin{tabular}{|c|c|c|}
\hline Anthropometric measurement & Number & Percent \\
\hline \multicolumn{3}{|l|}{ A. Weight (in kg.) } \\
\hline$<35$ & 16 & 4.1 \\
\hline $35-40$ & 75 & 19.2 \\
\hline $40-45$ & 170 & 43.6 \\
\hline $45-50$ & 69 & 17.7 \\
\hline $50-55$ & 32 & 8.2 \\
\hline $55-60$ & 24 & 6.2 \\
\hline$\geq 60$ & 4 & 1.0 \\
\hline Total & 390 & 100 \\
\hline \multicolumn{3}{|c|}{ Mean \pm SD:- 41.5 \pm 5.8 Range-32-62 } \\
\hline \multicolumn{3}{|l|}{ B. Height (in cm.) } \\
\hline$<145$ & 24 & 6.2 \\
\hline $145-150$ & 116 & 29.7 \\
\hline $150-155$ & 158 & 40.5 \\
\hline $155-160$ & 72 & 18.5 \\
\hline$\geq 160$ & 20 & 5.1 \\
\hline Total & 390 & 100 \\
\hline
\end{tabular}

Note- Table 1.2.1: Continued on next page

Table.4 Distribution of Body Mass Index of tribal women based on Chronic Energy Deficiency (CED) classification $(n=390)$

\begin{tabular}{|l|c|c|c|}
\hline Class & BMI & Number & Percent \\
\hline CED Grade III (Severe) & $<16.0$ & 44 & $\mathbf{1 1 . 3}$ \\
\hline CED Grade II (Moderate) & $16.0-17.0$ & 47 & $\mathbf{1 2 . 1}$ \\
\hline CED Grade I (Mild) & $17.0-18.5$ & 130 & $\mathbf{3 3 . 3}$ \\
\hline Low Weight - Normal & $18.5-20.0$ & 76 & $\mathbf{1 9 . 5}$ \\
\hline Normal & $20.0-25.0$ & 78 & $\mathbf{2 0 . 0}$ \\
\hline Obese & $\geq 25$ & 15 & $\mathbf{3 . 8}$ \\
\hline Total & & 390 & $\mathbf{1 0 0 . 0 0}$ \\
\hline \multicolumn{2}{|r|}{ Mean \pm SD $=\mathbf{1 8 . 7} \pm \mathbf{2 . 6}$} & Range 13.7 - 28.4 \\
\hline
\end{tabular}

Table.5 Distribution of females according to their haemoglobin level excluding pregnant women $(n=103)$

\begin{tabular}{|l|c|c|c|}
\hline Diagnosis & Haemoglobin $(\mathbf{g m} / \mathbf{d l})$ & No. & \% \\
\hline Severe & $<7.0$ & 2 & $\mathbf{1 . 9}$ \\
\hline Moderate & $7.0-9.9$ & 58 & $\mathbf{5 6 . 3}$ \\
\hline Mild & $10.0-11.9$ & 32 & $\mathbf{3 1 . 1}$ \\
\hline Normal & $\geq 12$ & 11 & $\mathbf{1 0 . 7}$ \\
\hline Total & & 103 & $\mathbf{1 0 0}$ \\
\hline \multicolumn{2}{|c}{ Mean \pm SD: 9.8 $\pm \mathbf{1 . 4}$ Range: $\mathbf{6 - 1 2 . 8}$} \\
\hline
\end{tabular}


Table.6 Compares prevalence of anaemia in different tribal area

\begin{tabular}{|l|c|c|c|c|}
\hline \multirow{2}{*}{ Study Groups } & \multicolumn{4}{|c|}{ \% Of women with different forms of Anaemia } \\
\cline { 2 - 5 } & $\begin{array}{c}\text { Anaemia over } \\
\text { all Hb<12.0 } \\
\text { gm/dl }\end{array}$ & $\begin{array}{c}\text { Mild Anaemia } \\
\text { Hb 10.0-11.9 } \\
\text { gm/dl }\end{array}$ & $\begin{array}{c}\text { Moderate } \\
\text { Anaemia Hb }\end{array}$ & $\begin{array}{c}\text { Severe } \\
\text { Anaemia } \\
\text { Hb<7.0 gm/dl }\end{array}$ \\
\hline $\begin{array}{l}\text { Tribal women in Naugarh Present } \\
\text { Study }\end{array}$ & 89.3 & 31.1 & 56.3 & $\mathbf{1 . 9}$ \\
\hline $\begin{array}{l}\text { Tribal women in Jharkhand (Maiti } \\
\text { and Unisa, 2003) }\end{array}$ & 74.8 & 39.1 & 33.1 & $\mathbf{2 . 6}$ \\
\hline $\begin{array}{l}\text { Kanikkar Women (Prema and } \\
\text { Thomas, 1992) }\end{array}$ & 60.0 & 50.0 & 10.0 & - \\
\hline $\begin{array}{l}\text { Oraon Women of Bihar } \\
\text { (Chandrasekhar et al, 1997) }\end{array}$ & 100.0 & N.A.* & NA & NA \\
\hline $\begin{array}{l}\text { Jenu Kurubas Women of Karnataka } \\
\text { (Rao et al, 1993) }\end{array}$ & 100.0 & N.A. & NA & NA \\
\hline $\begin{array}{l}\text { U.P. State overall figure for all } \\
\text { women (NFHS-3, 2005-06) }\end{array}$ & $\mathbf{4 9 . 9 0}$ & $\mathbf{3 5 . 1}$ & $\mathbf{1 3 . 2}$ & $\mathbf{1 . 6}$ \\
\hline
\end{tabular}

N.A $=$ not available

It has been observed from the present study that slightly less than half $(46.8 \%)$ study females were short stature and thin. Anaemia was the commonest finding on clinical examination as more than two third $(67.7 \%)$ women were found clinically anaemic. The mean weight of the study subjects was 41.5 $\mathrm{Kg}$. The vast majority (approximately 85\%) of females had weight less than the weight of the reference women $(50 \mathrm{Kg})$. The average height was $151.3 \mathrm{~cm}$. The mean body mass index was 18.7. Only one -fifth $(20.0 \%)$ of the study subjects were normal (BMI-20.0 25.0). The percentage of obese (BMI $\geq 25)$ women was mere 3.8 percent. Nearly ninetenth $(89.3 \%)$ women were found anaemic according to the cut-off point $(\mathrm{HB}<12.0$ $\mathrm{gm} / \mathrm{dl}$ ) proposed by WHO. The mean haemoglobin level was $9.8 \mathrm{gm} / \mathrm{dl}$. Choudhary and Rahoda (2015) also reported that the overall prevalence of anaemia was 91.3 percent in rural and 86 percent among urban Jat women, showing a higher prevalence of anemia among older women (97 percent rural,90 percent urban) compared to middle aged women (88.0 Percent rural, 84 percent urban). Also according to the National Family Health survey -2 the prevalence of anemia among all women in the India sample was 52 percent. Occurrence of 100 percent anemia was observed among Munda women (a tribe) from Kolkata city, India. Similar studies (Dobhal and Raghvanshi, 2011) reported that in all the age groups, rural women were found to have higher average hemoglobin concentration than the urban women. Also anaemia was more prevalent in the urban areas as compared to the rural area, which is contradictory to the findings of the previous studies. The reason for this may be higher forest and wildlife, along with consumption of green leafy vegetables and low worm infestation due to clean water in high altitude villages of the study (Table 6).

In conclusion, poor is the only word, represents the general overall nutritional status of the tribal females. Nutritional anaemia, vit-A and vit-C deficiencies are important problems in the study subjects. 
Majority of tribal females are underweight and stunted and having high prevalence of chronic energy deficiency.

\section{References}

Bagchi, T., 1994. Nutrition Profile. In: Bagchi T (Ed.): Profile of some Indian tribe (an anthroponutritional microstudy). Calcutta: Punihi Pustak, pp. 152-192.

Basu, S., 1992. Nutritional status, physical growth and health problems among the tribal population of Baster district (M.P). In: Tiwari PD and Tripathi RS (Ed.): Dimensions of Scheduled Tribes Development in India (Problems and Prospects). New Delhi: Uppal Publishing House, pp. 205-244.

Basu, S.K., 2001. Health status of tribal women in India. Retrieved on Aug 7, 2001 from: http://www.hsph.harvard.edu/ grnf / sAsia / Forums / Tribals /Tribals / MC

Chandrasekhar, U., Kowsalya, S., Saloni, S., 1997. Nutritional status of selected Oraon tribes of Bihar. The Indian Journal of Nutrition and Dietetics,37: 264-269.

Choudhary, M., Dashora, R., 2015 Effect of nutritional status on prevalence of anemia among females. Food science Research Journal, 6(1): 1-7

Darl, T.A., Bharathiraja, D., Pandit, 2017. A comparative study on nutritional and health status of tribal and nontribal reproductive women in anantnag district, Jammu and Kashmir International journal for innovative research in multidisciplinary field,3(2): 146- 159

Dobhal, N., Raghuvanshi, R.S., 2011. Indian, Journal of Nutrition and Dietetics, 48: 376-389.

Ghosh, J., 2006 Nutritional Status of Tribal Women: An Epidemiological Study Among Santal-Munda Tribes of North
24Th Parganas District of West Bengal, India. International journal of scientific research, (7): 48-51.

Government of India, 1983. National health policy document, Ministry of Health and Family Welfare, India

Government of India, 1994. National child survival and safe Motherland and Newborn care, Published by $\mathrm{MCH}$ Division, Ministry of Health and Family Welfare, Government of India, New Delhi.

Habicht, L.P., Davanzo, J., Butz, W.P., Meyers, 1989. The contraceptive role of breast - feeding. Journal of Population studies, 39(2): pp. 213 232.

Haque, M., Samantha, S., 1998. Health and nutrition among the Kora of Bankura, West Bengal: An anthropometric study. In: Chaturbhuj, S. (Ed.): Tribal culture and Identity. New Delhi: Sarup and Sons, pp.289-294.

Health care and health among the tribal women in Jharkhand: Evidences from NFHS. Retrieved Jan 15, 2003,from http://balasainet.com/projectreports/su tapasayeed.pdf

ICMR, 1990. A report of the expert group of the Indian Council of Medical Research: Nutrient requirements and recommended dietary allowances for Indians.

Jellife, D.B., 1966. The assessment of the nutritional status of the community. Monograph Series, WHO.

Kamath, R., Majeed, J. A., Chandrasekaran, V., and Pattanshetty, S. M., 2013. Prevalence of Anemia among Tribal Women of Reproductive Age in Udupi Taluk, Karnataka Journal of Family and Medical Primary Care, 2(4): 345-348.

Kaur, P., Singh, G., Pandey, S.S., 1984. Anaemia in tribals of Adhaura, Rohtas Bihar. Indian Journal of Public 
Health, XXVIII. I Jan-Mar: 4-7.

Krasovec, L., 1991. Prepregnancy weightBackground Issues. In: Krasoveck, K., Anderson, M.A., (Ed.): Maternal Nutrition and pregnancy outcomes, Anthropometric assessment. Washington D.C: Pan American Health Organization. Scientific publication No. 529, pp. 214

Kumar, P., Vijay, Singro, C.S., Mitra, M., 1989. Food consumption pattern and nutritional status of Kamars of Raipur (M.P): A pilot study In: Tiwari PD and Sharma (Ed.): Tribal Ecosystem and malnutrition. New Delhi: Northern Book Centre, pp-165-177.

Kupputhai, U., Mallika, N., 1993. Nutritional status of adult women belonging to khond, Gadaba and Porja tribes of Andhra Pradesh. The Indian Journal of Nutrition and Dietetics, 30: 173179.

Laxmaiah A et al., 2007. Diet and Nutritional Status of Tribal Population in ITDA project areas of Khammam District, Andhra Pradesh. J.Hum.Ecol, 21 (2): 79-86.

Patel, M. L., Deonanda, Raywat, 2017. Factors associated with body mass index among slum dwelling women in India: an analysis of the 2005-2006 Indian National Family Health Survey. International Journal of General Medicine, 10: 27-31

Mohanty, A.K., Sahu, P.N., Jana, G.C., 1992. Nutritional anthropometry of tribal adults. In: Tiwari, P.D. and Tripathi, R.S. (Ed.): Dimensions of Scheduled Tribes Development in India (Problems and Prospects). New Delhi: Uppal Publishing House, pp. 187-204.

Mohapatra, A., et al., 2001. Nutritional status of rural Oriya women from drought affected Kalahandi District of Orissa. The Indian Journal of Nutrition and Dietetics, 38: 403-411.
Moitra, A., Choudhary, R.P., 1991. Food habits and anthropometry of two tribes of Rajmahal hills, Bihar. Indian Journal of Medical Research, (B) 94: 64-70.

Murali, I., 1988. Evolution and select issues related to rural health delivery systems. In: background document "National Conference on Health for all leadership." New Delhi: National Institute of Health and Family Welfare, pp. 1-28.

National Family Health Survey-2 1998-99, India - Uttar Pradesh. International Institute for Population Sciences Mumbai and Measure DHS +, ORC Macro Calverton, Maryland, USA 2001.

National Nutrition Monitoring Bureau, 2003. Prevalence of micronutrient deficiencies. $\quad N N M B \quad$ Report No.22.Hyderabad: National Institute of Nutrition.

Official Home Page of National Family Health Survey-3 (2005-06). Retrieved January 5, 2009, from http://www.nfhsindia.org/data/india/in dch7.pdf

Prema, L., Felsy, T., 1992. Nutrition and health problems faced by Kanikkar women. In: Tiwari, P.D. and Tripathi, R.S. (Ed.): Dimensions of Scheduled Tribes Development in India (Problems and Prospects). New Delhi: Uppal Publishing House, pp. 245-258

Rao, D.H., Bhrahmam, G.N.V., Rao, N.P. 1993. Health and Nutritional Status of the Onge of little Andaman Islanders. In: Basu, A., Sarkar, J., and Danda, A.K. (Ed.): Studies on small population. Calcutta: Indian Anthropological society, pp. 69-78.

Rao, D.H., Brahmam, G.N.V., Rao, K.M., Reddy, C.G., Rao, N.P., 1993. Assessment of nutritional status of Jenu Kurubas-a primitive tribe of 
Karnataka. The Ind J Nutr Dietet,30: 66-71.

Rao, K.M., Balakrishna, N., Arlappa, N., Laxmaiah, A., Brahmam, G.N.V. 2010. Diet and Nutritional Status of Women in India. J Hum Ecol, 29(3): 165-170.

Rao, K.M., Kumar, R.H., Venkaiah, K., Brahmam, G.N.V., 2006. Nutritional status of Saharia- A Primitive Tribe of Rajasthan. Journal of Human Ecology. 19 (2): 117-123.

Rao, V.G., Sugunan, A.P., Sehgal, S.C., 1998. A profile of demographic and nutritional status of shompens-A Primitive Mongoloid Tribe of Great Nicobar. Indian Journal of Community Medicine, Vol XXIII No. 1 Jan- Mar: 38-41.

Saha, S.S., 1980. Anthropometry in genetic demography and anthropometry of Muria tribe (Narayanpur Muria, Bastar) New Delhi: Mittal Publications.

Seshadri, S., 1998. A data base on Iron Deficiency Anaemia (IDA) in India: Prevalence Causes, Consequences and Strategies for Prevention, Vadodara. M.Sc.Thesis, Unpublished. Gujarat: Maharaja Sayajirao University of Baroda.

Sharma, V., Sharma, A., 1993. The status of women fertility and family planning among tribals of south Rajasthan. Journal of family welfare, 39(4): 2025.

Singh, N., 1997. A study on nutritional profile of a tribal community of Naugarh Block Varanasi district. M.Sc.
Dissertation, Unpublised. Varanasi: Banaras Hindu University.

Singh, T.P., 2001. Ecology culture and tribal women's health: An analysis in Souvenir National Seminar on Tribal Health in India, New Delhi: National Institute of Health and family welfare.

Smitha, S., Mathew, S., 1998. Nutritional status of tribal adolescents of village Gogunda Rajasthan. The Indian Journal of Nutrition and Dietetics,25: 281-287.

Stolzfus, R.J., Dreyfuss, M.L., 1998. Guidelines for the use of iron supplements to prevent and treat Iron deficiency anemia. International Nutritional Anemia Consultative Group. Washington DC: International life Sciences Institute Press.

Taneja, P.V., Saxena, M. 1998. Nutritional Anthropometry of Bhil Women in Jhabua District of Madhya Pradesh. The Indian Journal of Nutrition and Dietetics, 35: 98-102.

Tanuja, D., Kamrakar, V., Sampath, Kumar, S., Jeyalakshmi, S., and Abel, R.,1995. Nutritional Status of tribal women in Bihar. Journal Man in India, 75(2): 209-214

WHO, 1968. Techn Rep Nutritional anaemias. Ser No. 405. Geneva.

World Bank, 1996. Development in practice, improving woman's health in India: World Bank.

Yadav, R.J., Singh, P., Kumar, A., 1999. Nutritional status of tribals and nontribals in Bihar. Indian Journal of Preventive and Social Medicine, 30 (3 and 4): 101-6.

\section{How to cite this article:}

Namita Singh. 2019. Nutritional Status of Tribal Women of Reproductive Age Group in Naugarh Block, Chandauli District. Int.J.Curr.Microbiol.App.Sci. 8(07): 953-966. doi: https://doi.org/10.20546/ijcmas.2019.807.115 